\title{
Endo and exo aortic morphometry [endoluminal] in the aortic arch and its branches
}

Faculty of Medicine, University “Ovidius" of Constanta

\begin{abstract}
Our study was conducted by the examination of angioCT's, performing external measurements of aortic arch and the exo and endoaortic measurements of its three. The diameter of the thoracic aorta prior to the origin of the brachiocephalic arterial trunk was found with an average of $31.65 \mathrm{~mm}$ and below the left subclavian artery origin we found an average diameter of $24.3 \mathrm{~mm}$. The brachiocephalic arterial trunk had an average diameter of $11.575 \mathrm{~mm}, 6.05$ at carotid artery level and $9.05 \mathrm{~mm}$ at the level of the left subclavian artery. The endoaortic average diameter of the brachiocephalic arterial trunk: horizontally, 13.0 $\mathrm{mm}$ and vertically $11.7 \mathrm{~mm}$; left common carotid artery horizontal diameter was $10.5 \mathrm{~mm}$ and $9.7 \mathrm{~mm}$ vertically and the left subclavian artery have $14.1 \mathrm{~mm}$ horizontally and $10.8 \mathrm{~mm}$ vertically.
\end{abstract}

Keywords: aortic arch, exo- and endo-luminal morphometry

\section{Iliescu D. M.}

Department of Anatomy, Faculty of medicine,

University "Ovidius" of Constanţa

Aleea Universitatii, Nr. 1, Campus B

Constanţa, Romania

e-mail:dan@anatomie.ro

\section{Introduction}

The aortic arch (Arcus aortae) begins immediately after aortic bulb (Bulbus aortae), with a superior and posterior oblique direction to the left, passing from the anterior mediastinum in the posterior mediastinum, by crossing the left side of the tracheal bifurcation [1]. According to [2 and 3] it begins posterior to the second right sterno-costal joint, so at the same level with the sternal angle and ends on the left side of the fourth cervical vertebra. According to [4], the aortic arch is oriented obliquely, anterior-posterior and right to left, so that its left face is oriented antero-lateral and the right face posteromedial. Is "riding" on the left bronchus and is in both halves of the mediastinum. From its origin to the end, the aortic arch caliber slightly diminishes, despite the voluminous collateral branches that it gives; aorta is a passage and distribution arterial trunk [4]. According to [5], after issuing its branches, the aortic arch diminishes its caliber by $4 \mathrm{~mm}$. The projection of the aorta is located slightly lower to the sternal notch, the distance between the sternal fork and the aortic arch being $20 \mathrm{~mm}$ [4]. Normally, the aortic arch never exceeds the sternal notch. The aortic arch branches are represented by the arterial brachiocephalic trunk 
(Truncus brahiocephalicus), the left common carotid artery (Arteria carotis communis sinister) and the left subclavian artery (Arteria subclavia sinister), which originate from different levels of the aortic arch. Among them, the brachiocephalic trunk is the most voluminous branch of the aortic arch, having a length of $35 \mathrm{~mm}$ and a diameter of $15 \mathrm{~mm}[1,4,5,6,7,8,9,10]$.

\section{Materials and methods}

Our study was conducted by consulting angioCT's from by Pozimed Diagnostic Center in Constanta, on a GE LightSpeed CT VCT64 Slice CT. External measurements were performed at the at the following levels of aortic arch: anteriorly to the origin of the brachiocephalic arterial trunk and after the origin of the left subclavian artery, as well as exo and endoaortic measurements of the three branches of it. The trial was performed on a total of 48 angioCT's for external measurements, 14 from females and 34 males, and only 9 cases for the endoaortic measurements.

\section{Results}

The diameter of the thoracic aorta anteriorly to the origin of brachiocephalic arterial trunk was found with an average of $31.65 \mathrm{~mm}$, in females being 27.9 $\mathrm{mm}$ in diameter and $31.65 \mathrm{~mm}$ for males. The aortic arch diameter below the left subclavian artery origin was $24.3 \mathrm{~mm}$ in average, with $22.7 \mathrm{~mm}$ in females and $24.3 \mathrm{~mm}$ in males. Brachiocephalic arterial trunk had an average diameter of $11.575 \mathrm{~mm}$, with $11.9 \mathrm{~mm}$ in females and $11.8 \mathrm{~mm}$ in males. The left common carotid artery average diameter was $6.05 \mathrm{~mm}$, with $5.15 \mathrm{~mm}$ in females and $5.45 \mathrm{~mm}$ in males. The average diameter of the left subclavian artery had an average of $9.05 \mathrm{~mm}$, with $7.65 \mathrm{~mm}$ in females and males $10.25 \mathrm{~mm}$. Regarding the endoaortic diameters of the aortic arch branches, the brachiocephalic arterial trunk showed an average horizontal diameter of $13.0 \mathrm{~mm}$ and $11.7 \mathrm{~mm}$ for the vertical diameter. In the left common carotid artery the horizontal endoaortic average diameter was $10.5 \mathrm{~mm}$ and 9.7 $\mathrm{mm}$ vertically. For the left subclavian artery the horizontal endoaortic average diameter was $14.1 \mathrm{~mm}$ and $10.8 \mathrm{~mm}$ the vertical one.

\section{Discussion}

From the endoaortic measurements results, after comparing the vertical and the horizontal diameters of the aortic arch branches, that all orifices are oval, with the longest axis oriented horizontally, a more pronounced aspect being at the opening of the left subclavian artery, at which the horizontal diameter was greater than the vertical one by 3.3 $\mathrm{mm}$; the next was the diameter of the brachiocephalic arterial trunk, where the average difference was 1.3 $\mathrm{mm}$. Only the left common carotid artery orifice was closer to the round shape, were the difference between the horizontal and the vertical diameters was $0.8 \mathrm{~mm}$.

Comparing between them the average diameters of the orifices of the aortic arch branches, the largest horizontal diameter is the one of the left subclavian artery, which is higher by $1.1 \mathrm{~mm}$ than the diameter of the brachiocephalic arterial trunk and 3.6 $\mathrm{mm}$ than the horizontal diameter of the left common carotid artery. So the horizontal diameter of the left subclavian artery is lower by $19.23 \%$ than the same brachiocephalic arterial trunk diameter and 25.53\% than the horizontal diameter of the left subclavian artery. The brachiocephalic arterial trunk horizontal diameter is $17.80 \%$ lower than the horizontal diameter of the left subclavian artery. The average vertical diameter of the orifices of the three branches of the aortic arch is the largest at the brachiocephalic trunk, being higher by $2.0 \mathrm{~mm}$ than the orifice of the left common carotid artery and $0.9 \mathrm{~mm}$ than the orifice 
of the left subclavian artery. So the average vertical diameter of the left common carotid artery is lower than the same diameter of the brachiocephalic arterial trunk with $17.10 \%$ and by $10.19 \%$ than the diameter of the left subclavian artery. The vertical diameter average of the left subclavian artery is smaller than the vertical diameter of the brachiocephalic arterial trunk with $7.69 \%$.

Comparing the averages of the horizontal diameters of the orifices of the aortic arch branches with external diameters of these branches at their origin from the aortic arch, we always found that the orifices had larger sizes, which are higher by $11.24 \%$ for the brachiocephalic arterial trunk, with $17.36 \%$ for the left common carotid artery and $15.74 \%$ for the left subclavian artery.

In the literature that we had the opportunity to consult we have not encountered references to the endoluminal sizes of the aortic arch and its branches, which is why we refer comparative only on the external diameters of the aortic arch branches.

Table no. I - The brachiocephalic arterial trunk diameter

\begin{tabular}{||l|c||}
\hline AUTHOR & $\begin{array}{c}\text { THE } \\
\text { BRACHIOCEPHALIC } \\
\text { ARTERIAL TRUNK }\end{array}$ \\
\hline \hline Paturet & $13 \mathrm{~mm}$ \\
\hline \hline Kamina & $13 \mathrm{~mm}$ \\
\hline \hline Bouchet & $13 \mathrm{~mm}$ \\
\hline \hline Shin Young & $11.4 \mathrm{~mm}$ \\
\hline \hline Testut & $12-15 \mathrm{~mm}$ \\
\hline \hline Gorun & $14 \mathrm{~mm}$ \\
\hline \hline Personal cases & F: $8.3-15,5 \mathrm{~mm}$ \\
M: $9.1-14.5 \mathrm{~mm}$
\end{tabular}

The maximum diameter of the brachiocephalic trunk that we found in females is $15.5 \mathrm{~mm}$ and 14.5 $\mathrm{mm}$ male; being one single case; we considered out the value immediately below it, in females being $9.3 \mathrm{~mm}$ and $12.8 \mathrm{~mm}$ in males. This shows that the brachiocephalic trunk diameter is smaller in females than in authors refer with differences of 2.1 compared to [11], $3.7 \mathrm{~mm}$ compared to [4,6,7,10], with a difference of $4.7 \mathrm{~mm}$ compared to [10], and a difference of $5.7 \mathrm{~mm}$, as compared to [6.7]. In males these differences are smaller, of only $0.2 \mathrm{~mm}$ compared to $[4,6,7,12]$, lower by $1.2 \mathrm{~mm}$ compared to [12], less than $2.2 \mathrm{~mm}$ compared to [6.7] but higher by $1.4 \mathrm{~mm}$ as compared to [11].

Table no. II - The left common carotid artery diameter

\begin{tabular}{||l|c||}
\hline AUTHOR & $\begin{array}{c}\text { THE LEFT COMMON } \\
\text { CAROTID ARTERY }\end{array}$ \\
\hline Paturet & $9-10 \mathrm{~mm}$ \\
\hline Kamina & $9 \mathrm{~mm}$ \\
\hline Bouchet & $8 \mathrm{~mm}$ \\
\hline Shin Young & $9.5 \mathrm{~mm}$ \\
\hline Turgut & $13 \mathrm{~mm}$ \\
\hline Gorun & $9 \mathrm{~mm}$ \\
\hline Personal cases & F: $4.6-5.7 \mathrm{~mm}$ \\
M: $5.1-5.8 \mathrm{~mm}$
\end{tabular}

In the left common carotid artery the diameters that we found are also lower than the literature, but this time with greater differences, the differences in females are downwards from 4.3-4.4 mm compared to [4] of 3.3 to $4.4 \mathrm{~mm}$ compared to $[9,12]$ of 2.3 to $3.4 \mathrm{~mm}$ compared to [10], of 3.8 to $4.9 \mathrm{~mm}$ compared to [11], and 7.3 to $9.4 \mathrm{~mm}$ compared to [13], but we tend to believe that this difference is exaggerated. In males, the downwards differences are a bit lower than in females, being 2.2 to $2.9 \mathrm{~mm}$ compared to [4] 3.2 to $4.9 \mathrm{~mm}$ compared to [6,7,9], 3 compared to [7], to 4.4 compared to [13], from 4.2 to $4.9 \mathrm{~mm}$ compared to [4] and again exaggerated, of 7.2 to 7.9 mm compared to [6].

Table no III - The left subclavian artery diameter

\begin{tabular}{||l|c||}
\hline AUTHOR & $\begin{array}{c}\text { THE LEFT } \\
\text { SUBCLAVIAN ARTERY }\end{array}$ \\
\hline Paturet & $9-10 \mathrm{~mm}$ \\
\hline Kamina & $9-10 \mathrm{~mm}$ \\
\hline Bouchet & $9-10 \mathrm{~mm}$ \\
\hline Shin Young & $10,6 \mathrm{~mm}$ \\
\hline Gorun & $10 \mathrm{~mm}$ \\
\hline Personal cases & $\begin{array}{r}\text { F: } 5.3-10 \mathrm{~mm} \\
\text { M: } 7.7-12.8 \mathrm{~mm}\end{array}$ \\
\hline
\end{tabular}

The left subclavian artery maximum diameters 
in females are similar to those from the consulted literature on the maximum diameter found by us, only [11] finding a $0.6 \mathrm{~mm}$ greater diameter. Differences exist in relation with the minimum diameter, being larger by $3.7 \mathrm{~mm}$ compared to $[4,9,10], 4.7 \mathrm{~mm}$ compared to [12] and $5.3 \mathrm{~mm}$ compared to [11]. In males, the maximum diameter was higher by $2.8 \mathrm{~mm}$ compared to $[4,6,9,10]$ and $2.2 \mathrm{~mm}$ compared to [11]. Regarding the minimum diameter we found it smaller by $1.3 \mathrm{~mm}$ compared to $[4,9,10]$, by $2.3 \mathrm{~mm}$ than [12] and by $2.9 \mathrm{~mm}$ compared to [11].

\section{Conclusions}

The aortic arch and its collateral branches, due to the special importance they presents, have been studied since ancient times, and the increasing number of surgeries on that region of the vascular system and the appearance of new anatomical variations, rare or unspecified in classical anatomy, impose an update and a thorough study of the morphology of these arteries. Like [14], we found that there is a direct link between the diameter of the aortic arch and its collateral branches origin. The relative caliber of the arterial branches of the aortic arch depends on the position of their origin from the aortic arch: in arches were the branches had their origins in the horizontal segment, the first branch was the largest, being more voluminous than in cases that they originated within the ascending segment. We also found that the left common carotid artery has a lower caliber when originates in the brachiocephalic trunk than in cases where its origin is in the aortic arch. In the case of the left subclavian artery, its caliber is frequently more voluminous than in cases that originated from the descending segment of the aortic arch. According to [9], the aortic arch shape depends on the morphological individual type; in the sagittal type subject the aortic arch is narrow and situated in a plane approximately sagittal, while in the frontal type subject being larger and located in a more frontal plane, an aspect met in most cases of our study.
The study of this arterial segment presents a particular interest from the terms of morphology, being part of great vessels of the body, a physiological interest, considering its functions, a pathophysiologic and clinical interest, because of the diseases (congenital or acquired) frequency diagnosed at this level, a radiological interest through frequent scans and simple angiography and CT in the medical practice and a surgical interest by developing impressive cardio-vascular surgery, heart and aorta grafts, the coronary artery bypass, ligated and carotid grafts, etc. It cannot perform any medical intervention within this sector without prior accurate and thorough knowledge of its morphology.

\section{References}

1. Nguyen, H. (1996). L'aorte thoracique. In J.P.Chevrel (Eds), Anatomie Clinique. Le Tronc. (pp 176, 182-184, 186-187). Paris: SpringerVerlag.

2. Moore, L.K. \& Dalley, F.A. (2001) Anatomie médicale. Aspects fondamentaux et applications cliniques. Bruxelles: De Boeck Université.

3. Schunke, M., Schulte, E., Schumacher, U, Voll, M. \& Wesker K. (2007). Atlas d'Anatomie. Cou et organes internes. Paris: Maloine.

4. Paturet, G. (1958) Traite d'anatomie humaine, Tome III. Paris: Masson.

5. Standring, S. (2005). Gray's Anatomy. The Anatomical Basis of Clinical Practice. Edinburg, London, New York, Sydney, Toronto: Elsevier Churchill Livingstone.

6. Testut L. (1929). Traite d'anatomie humaine. Angiologie. Paris: Gaston\&Cie.

7. Testut L. (1924). Traité d'anatomie humaine. Deuxième partie. Le péricarde et le coeur. Les artères et les veines du tronc. Paris: Gaston Doin.

8. Rouvière, H. \& Delmas, A. (1997) Anatomie Humaine déscriptive topographique et fonctionnelle. Tome 2 Tronc. (14ed). Paris: Masson. 
9. Kamina, P. (2002). Précis d'anatomie clinique. Tome II. Paris: Maloine.

10. Bouchet, A. \& Cuilleret J. (1991). Anatomie topographique, descriptive et topographique. 2. Le cou. Le thorax. Paris: Simep.

11. Young, S., Yong-Gu, C., Won-Han, S., SooBin, I., Sun-Chul, H. \& Bum-Tae, K. (2008). A Morphometric Study on Cadaveric Aortic Arch and Its Major Branches In 25 Korean Adults: The Perspective of Endovascular Surgery. J.Korean. Neurosurg.Soc., 44, 78-83.

12. Gorun, M. \& Mihalache, C. (2010) The Branches of the Aortic Arch. Three case Presentation of anatomical variants. Ars.Med.Tomit., 16(2), 9496.

13. Turgut, H.B., Peker, T., Anil, A. \& Barut, C.
(2001). Patent ductus arteriosus, large right pulmonary artery and brachiocephalic trunk variation. A case report. Surg.Radiol.Anat., 23, 69-72.

14. Grande, N.R., Costa, A., Silva, E., Sousa, P.A. \& Aguas, A.P. (1995). Variations in the Anatomical Organization of the Human Aortic Arch. A Study in a Portuguese Population. Bull. Assoc.Anat., 244, 19-22.

15. ******** (1988). Terminologia Anatomica. International Anatomical Terminology. Federative Committee on Anatomical Terminology 1988. Stuttgart: Thieme Verlag. 